\title{
GETTING AT THE MATHEMATICS: SARA'S JOURNAL
}

\author{
Bob Speiser and Chuck Walter, \\ Mathematics Education Laboratory, \\ Department of Mathematics Education, Brigham Young University
}

In this paper, we discuss issues in planning and conducting research into mathematics learning. We emphasize two central themes: (a) the learners' mathematics (especially the issues and ideas, in given problem situations, that learners choose to think about and to present, and (b) the kinds of knowledge that learners may be building (including their ideas about what mathematics is, and how people do, learn, use, communicate and understand it). While the first theme is at least partly mathematical, the second interweaves cognition and epistemology. Anchored in student data from an extended classroom teaching experiment in the mathematics of change, we focus on key choices needed to build narratives to help researchers capture, in detail, how students understand their own engagement with their mathematics.

According to Brousseau (1997), for example, learning takes place (or perhaps fails to take place) in the course of student-teacher interactions. These are seen as governed by (frequently tacit) understandings (the didactic contract) about what is to be learned, how learning can be demonstrated, and about the respective responsibilities of learner and teacher. To understand an act of learning, in this view, one needs to understand not only what was said and done, but also the nature of the underlying contract. And to change the way learning takes place - which is critical to implement needed reforms - the contract often must be renegotiated. Such negotiations, as we know, can hinge on central questions about mathematics: how we do it, how we learn it, what it is about, how we talk, display and write about it, and what constitutes proficiency. In this paper we will emphasize the mathematics, most especially to suggest possible ways, as researchers, to think about and work with students' presentations of their mathematics. We will focus here on one student's journal, and on how to build what we will call composite narratives, based on that journal and a careful choice of additional supporting data.

The present paper introduces several key ideas that will guide a group of papers now in progress, each one devoted to the work and thinking of one of six undergraduates (all majors in the arts) over three months, who participated in an extended classroom teaching experiment on representing and reasoning about change (Designing Calculus, BYU, 2002), led by the first author. ${ }^{1}$

Sara is a senior, concentrating in ballet. She began by working on a task designed earlier by diSessa and his coworkers, called the desert motion (diSessa \& Sherin, 2000; Sherin, 2000). In Figure 1 we reproduce top third of first page of her journal, which begins with her own statement of the problem.

\footnotetext{
${ }^{1}$ In addition to both authors, the research team includes Marin Turley, Tiffini Christensen and Joe Curtis.
} 
$\frac{\text { Math }}{9 / 10}$

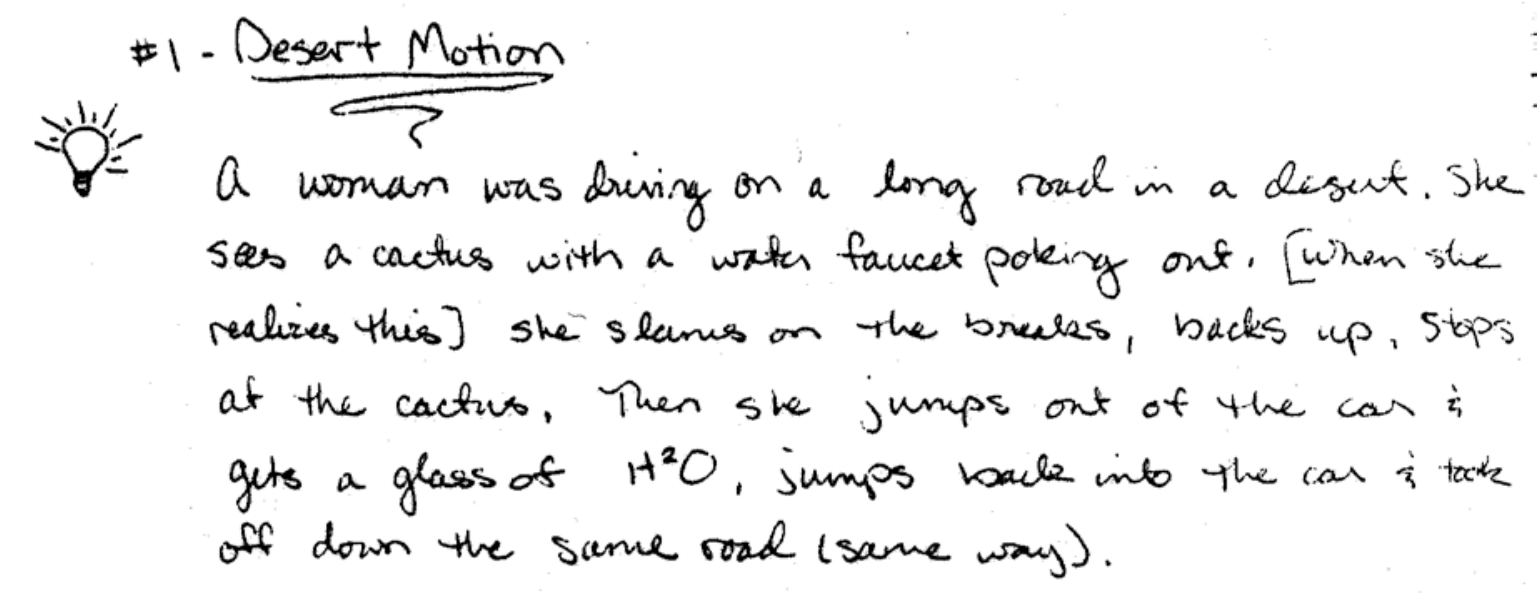

- Anralize this problem -

Figure 1. Sara's Journal: first page, top, September 10, 2002.

Sara's journal offers vivid presentations of her thinking. Later, she and two other students, by inventing a series of graphic, physical and kinesthetic representations, would discover ways to make connections between distance, speed and time, so that speed as rate of change, and distance as area under a graph of speed, became transparent to them. Figure 2, the rest of Sara's initial page, describes how she began to think about the crux issue of the desert motion problem: how to represent the motion of the car.

\section{at fivot I was concenned with solving this froblem - Ineven} really understand probkens like (atace $\times$ time-distance). It was hul for me to think of the sobdem in terms of mothimatical concepis. But when I thought about it in teruns of moremunt, and the sequence of events - morement is change, it became easien. We started by drawing putives.

Figure 2. Sara's journal: first thoughts, September 10, 2002.

To provide a starting point for analysis - and to illustrate the way we work with student presentations - we will trace how each such presentation (here a sequence of pictures, Figure 3) often serves two fairly distinct purposes (Dörfler, 2000): to present part of a learner's thinking to herself, and to provide a tool for communication to others. The journal entry shown in Figure 3 began as a collaboration, on the classroom whiteboard, with another student (Krista), as they modified initial sketches to be able to encode more 
information. This encoding was unpacked in class, triggered by other students' questions, before Sara drew her final version in her journal, based in part upon these interactions.
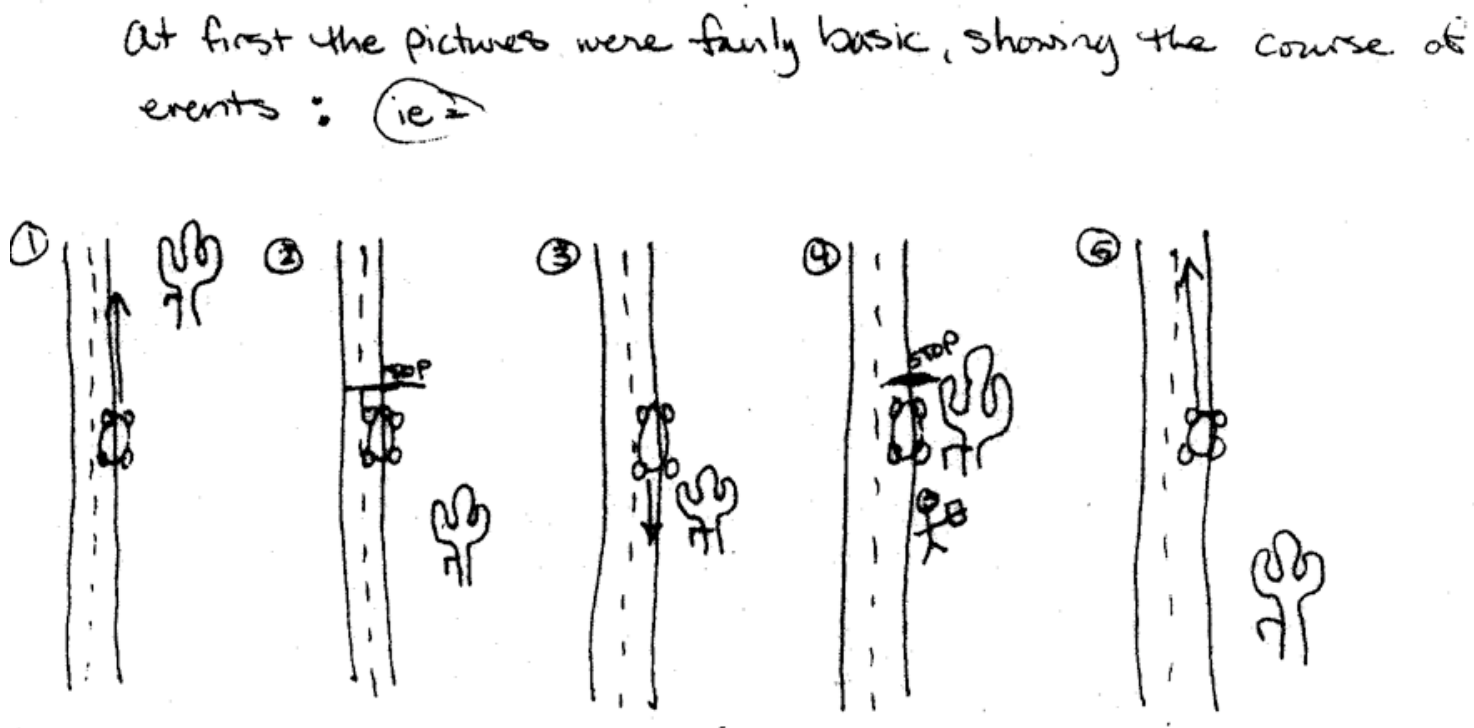

Figure 3. Sara's journal: first pictures, September 10, 2002.

Our theoretical perspective begins with mathematical activities (such as the desert motion) that are rich enough to elicit the construction of mathematically important processes and understandings. Here, as Sherin and diSessa found (diSessa \& Sherin, 2000; Sherin, 2000) with sixth-grade students, the desert motion task quickly led to cycles of construction, critique, and reconstruction, leading to increasingly detailed representations of the car's motion. As side effects, representations were proposed, modified, discarded and reshaped, culminating in the collective reinvention of what we would call the standard graphs, using (a) slopes to present rates of change and (b) areas defined by graphs of rates to present total changes. Following Dörfler (2000), we see such activities as prototypes (more precisely, mathematical prototypes) for the construction of particular mathematical meanings, in this instance local rates of change and global changes.

This emphasis on prototypes has implications for our research methodology. Because we focus on the building and the use of prototypes in the development of mathematical understanding, we need to follow student presentations over time, and trace the variety of ways in which the students work with them, both personally and in collective discourse. It is therefore natural to build narratives, in which students' thinking can be traced through close analysis of presentations where they demonstrate the reasons for their actions.

To build such narratives, we first locate critical events (Maher \& Martino, 1996), then trace the student presentations made in them to build a timeline that will anchor a composite narrative (Speiser, Walter \& Maher, 2003). In Sara's case, the timeline centers on selected entries from her journal. This initial timeline is next supplemented with selected videotaped segments of activities to which the journal (perhaps implicitly) refers, to produce a basic narrative. This basic narrative is annotated, somewhat in the style of 
open coding (Strauss, 1987), to identify emerging themes in student work and discourse, and to initiate more theoretical descriptions.

Based on Sara's journal, the desert motion and two later tasks provided prototypes, not just for mathematical constructions, but also for new ways of thinking. In November, for example, two months into the teaching experiment, she wrote:

- How mathematics has changed my way of thinking... ${ }^{2}$ In dance especially I feel like I think about movement in a more clear, analytical way. I think that when I am given a phrase of movement that travels across / through the space to music, knowing that RxT $=\mathrm{D}$ really makes a difference in the way I approach the movement. I know that if I need to travel a longer distance in the same amount of time, the Rate of Speed of my movement needs to proportionally increase. This has been a real revelation for me!

We shall call an activity an epistemological prototype when it anchors a new way of thinking (as arguments about block towers were for children in Maher's Kenilworth study, serving first as prototypes for particular proof strategies, but then as prototypes for the idea of proof).

As researchers, bearing in mind the different purposes that prototypes can serve, we approach the explicit mathematics that Sara discusses in her journal with a view toward building up descriptions of her learning process, based primarily on how she wrote about it. For Sara, the formula connecting distance, speed and time, referred to as problematic in her first journal entry (Figure 2) evolved into a major unifying theme throughout the course. Hence our descriptions of her mathematics would need to build from what she writes and does to understand this formula.

We return now to the larger research context. Sara's narrative is one of six. As our developing analysis has shown (to be explained in later papers), each student's narrative reflects its own unique trajectory, in which personal reflections interweave with group collaboration in different but closely related ways. As in (Speiser \& Walter, 1997, 2000; Speiser, Walter \& Maher, 2003), we could trace the classroom action as a single conversation, a collage of many voices leading to collective opportunities for understanding. But to gain more detail about the mathematics being built, and most especially how learners think about it, we will need to work in detail with the variety of students' personal reflections, thinking of journals and other narrative material as inscriptions which can serve the dual functions (a) of clarifying issues for oneself and (b) making such reflection vivid for an analytic reader. In this way prototypes arrive not just with features but as parts of learners' lives and histories.

In Sara's case, detailed analysis (to be reported later) of the composite narrative based on the journal entry quoted above, including its supporting video, indicates that graphs emerged for her as tools for anchoring new ways of thinking about her own motion, with the desert motion task as prototype. Thus the desert motion task (as carried through by our six learners) has functioned both as a mathematical and an epistemological prototype, in significantly different ways for different students. To the extent that it may also anchor an emerging understanding of the learning process, we might call it a pedagogical

\footnotetext{
${ }^{2}$ Her ellipsis dots.
} 
prototype. Our understanding of our students' mathematics, in particular, emerges from the students' presentations (such as Sara's journal and the classroom discourse that surrounds it in our narrative). Through these, we can learn about the mathematics that the students worked with, and about the kinds of knowledge that they built.

\section{References}

Brousseau, G. (1997). Theory of didactical situations in mathematics (N. Balacheff, M. Cooper, R. Sutherland, \& V. Warfield, Trans.). Dordrecht: Kluwer.

diSessa, A. A., \& Sherin, B.L.(2000). Meta-representation: An introduction. Journal of Mathematical Behavior, 19, 385-398.

Dörfler, W. (2000). Means for meaning. In P. Cobb, E. Yackel and K. McClain, (Eds.), Symbolizing and communicating in mathematics classrooms: Perspectives on discourse, tools, and instructional design (pp. 99-131). Hillsdale, NJ: Erlbaum.

Maher, C. A., \& Martino, A. M. (1996). The development of the idea of mathematical proof: A 5year case study. Journal for Research in Mathematics Education, 27(2), 194-214.

Sherin, B. L. (2000). How students invent representations of motion: A genetic account. Journal of Mathematical Behavior, 19, 399-441.

Speiser, R., \& Walter, C. (1997). Performing algebra: Emergent discourse in a fifth-grade classroom. Journal of Mathematical Behavior, 16, 39-49.

Speiser, R., \& Walter, C. (2000). Five women build a number system. Stamford, CT: Ablex.

Speiser, R., Walter, C., \& Maher, C. A. (2001). Representing change. In M. van den HeuvelPanhuizen (Ed.), Proceedings of the 25th Annual Meeting of the International Group for the Psychology of Mathematics Education (Vol.4, pp. 209-216). Utrecht, Holland.

Speiser, R., Walter, C., \& Maher, C. A. (2003). Representing motion: A learning experiment. Journal of Mathematical Behavior, to appear.

Strauss, A. (1987). Qualitative analysis for social scientists. Cambridge UK: University of Cambridge Press. 
Page Intentionally Left Blank 